\title{
Música en el IV centenario de la muerte de Cervantes
}

\author{
Ana Vega Toscano*
}

\begin{abstract}
Resumen
Durante el año 2016 se han sucedido numerosos actos de conmemoración del cuarto centenario del fallecimiento de Miguel de Cervantes; en muchos de ellos la música ha ocupado un lugar destacado. En esta nota resumimos algunas de esas iniciativas, con especial atención al Festival Internacional Cervantino de Guanajuato 2016.
\end{abstract}

Palabras clave: Cervantes; IV centenario; actividades musicales.

Title: Music in the fourth centenary of Miguel de Cervantes' death

\begin{abstract}
This note describe some musical activities organized in the Fourth Centenary of Miguel Cervantes' death, in particular the most relevant events of the International Cervantino Festival of Guanajuato 2016.
\end{abstract}

Keywords: Cervantes; Fourth Centenary; Musical Activities.

\section{Cómo citar este artículo / Citation}

Vega Toscano, Ana (2018). «Música en el IV centenario de la muerte de Cervantes», Anales Cervantinos. 50, pp. 353-360, https://doi.org/10.3989/anacervantinos.2018.016.

El cervantismo posee una gran fuerza como elemento dinamizador en la vida cultural desde muy diversos frentes, entre ellos el mundo musical, que ha encontrado en él a lo largo de los siglos una gran fuente de inspiración en

\footnotetext{
* Departamento de Música, Universidad Autónoma de Madrid. ana.vega@uam.es / ORCID iD: https://orcid.org/0000-0001-6053-8636.
} 
muy distintos actos y contenidos. La dinámica de conmemoraciones que preside desde hace años nuestra programación cultural ha tenido tradicionalmente un gran refuerzo en la celebración de la muerte de Cervantes, tanto en el recuerdo anual del día exacto, como en los aniversarios más redondos que abarcan evidentemente un año completo. La inmediatez de dos acontecimientos tan importantes como la edición de la segunda parte de Don Quijote de la Mancha y el fallecimiento del genial autor en años consecutivos, hacen que las conmemoraciones del centenario de estas dos efemérides acaben por fundirse en una sola realidad ampliada, que se añade así a la otra gran fecha en torno a Cervantes, la publicación de la primera parte del Quijote diez años antes. Ya históricamente, muchas empresas artísticas de temática cervantina han sido fruto de las distintas celebraciones o bien del III Centenario de alguna de estas fechas, o del 350. ${ }^{\circ}$ aniversario. En 2016 se ha vivido una cita especialmente destacada, el cuarto centenario del fallecimiento, y han sido muchos los actos programados en su entorno, en un año que ha sido noticia relevante en los distintos medios de comunicación, pues ocupó numerosas tribunas de opinión, y protagonizó en este sentido un verdadero debate político. Se comentó, como resumen al final de este año dedicado a Cervantes, que la dispersión marcó las distintas iniciativas, quizás por las circunstancias políticas inciertas que se atravesaban en la vida oficial española al inicio de 2016. El cervantismo, como piedra de toque en la vida política, ha cobrado desde hace más de un siglo una importancia creciente en la historia española, al igual que la relevancia de las distintas conmemoraciones de los más destacados centenarios cervantinos en la incentivación e incremento del campo del propio cervantismo en sus más variadas facetas ${ }^{1}$.

Al cerrar el año, la comisión encargada desde el Ministerio de Educación, Cultura y Deporte de los actos conmemorativos presentó un balance de cerca de 500 actos en todo el mundo, entre los que la música en sus distintas vertientes tuvo una amplia presencia. Las principales instituciones culturales promovieron iniciativas propias, en muchos casos con colaboraciones entre ellas, que abarcaron los campos habituales en ese tipo de acontecimientos. En primer lugar, la interpretación en conciertos y grabaciones del amplio repertorio relacionado con el mundo del cervantismo en sus dos aspectos más destacables: con las obras inspiradas en la obra de Cervantes a lo largo de la historia, o con la moderna tendencia de acercarse a una selección musical de la época del autor, relacionada de mil maneras posibles a su obras. Músicas que nos aproximan a todos los géneros, desde la ópera o el ballet hasta la música de cámara, pasando por las músicas incidentales. Otro apartado esencial es el representado por el estudio musicológico y la investigación del cervantismo musical, marcado por conferencias, publicaciones o congresos, así como por exposiciones, a lo que se suma la catalogación de los fondos

1. El estudio de la vertiente musical de la celebración del III Centenario de la publicación de la primera parte del Ingenioso Hidalgo Don Quijote de la Mancha, realizado por Adela Presas, apunta al interés político de las celebraciones ya a principios del siglo XX (Presas 2007). 
pertenecientes a este campo, y hoy en día al decisivo impulso de digitalizar y disponer el acceso online a dichos recursos. Este último campo, aportación fundamental en las iniciativas culturales de estos últimos años, ha sido quizás uno de los más destacados y perdurables aportes de las conmemoraciones de este año dedicado a Cervantes.

Desde Acción Cultural Española se promocionaron conciertos que abarcaron desde la música aludida por Cervantes en su obra hasta el repertorio contemporáneo de nueva creación: en el primer caso, un ejemplo serían los conciertos de Capella de Ministrers o Raquel Andueza y La Galanía en Les Grands Concerts de Lyon ${ }^{2}$, mientras en el segundo apartado podemos encontrar Estremada Armonía: Cervantes en el piano español contemporáneo, concierto de la pianista Marta Espinós que se presentó en la Biblioteca Nacional de España ${ }^{3}$. Igualmente, Acción Cultural Española apoyó al Teatro Real en las funciones que ofreció en el transcurso de su temporada de una de las obras fundamentales del repertorio musical cervantino y de la creación operística española, El Retablo de Maese Pedro, de Manuel de Falla, en versión escénica de Enrique Lanz, creador de la compañía de títeres Etcétera, y además nieto de Hermenegildo Lanz, el polifacético artista plástico granadino que trabajó precisamente con Manuel de Falla en el estreno de la obra ${ }^{4}$. El Teatro Real colaboró a su vez con los Teatros del Canal de Madrid para otra de las representaciones operísticas de carácter cervantino propuestas para este año de homenaje a Cervantes en Madrid, dentro de la creación actual: la ópera corta de cámara de Tomás Marco El caballero de la triste figura ${ }^{5}$. La ópera de cámara contemporánea española ya había contado en las celebraciones cervantinas del año anterior con otro título a sumar, en esa ocasión en estreno absoluto: Pensares de Rocinante, del compositor José Buenagu con libreto de Justo Merino, representada en versión semi-escénica en el Auditorio de Madrid en el XVII Ciclo de Grandes Autores e Intérpretes de la Música de la $\mathrm{UAM}^{6}$.

Estos son solo algunos ejemplos de los conciertos y representaciones operísticas que acogieron los distintos festivales a lo largo del año, impulsa-

2. Cervantes, Don Quichotte et la musique fue la propuesta de Capella de Ministrers, y Folies d'Espagne. Yo soy la locura, la de Raquel Andueza y La Galanía.

3. Celebrado el 22 de abril con el estreno de obras encargadas a Tomás Marco, Benet Casablancas, Carlos Cruz de Castro, Mercedes Zavala, a las que se añadieron dos obras más, de Manuel Angulo y José Zárate.

4. Las funciones tuvieron lugar entre el 23 y el 30 de enero, con la dirección de Josep Vicent y la interpretación de Isidro Anaya, Gerardo López y Marisa Martins, con la JORCAM. Se trata de una coproducción entre varios organismos estrenada el año 2009 en el Teatro del Liceo de Barcelona.

5. Obra encargo de la antigua Sociedad Estatal de Actividades Culturales para el centenario cervantino, estrenada en Albacete el año 2005. Las representaciones tuvieron lugar el 26, 28 y 30 de enero, con un reparto encabezado por Alfredo García y María José Suárez, la dirección de escena de Guillermo Heras y la musical de Manuel Coves, al frente de la Orquesta Sinfónica de Madrid.

6. Encargo de la Universidad Autónoma de Madrid, y vinculado al proyecto internacional de Investigación de Excelencia Multidisciplinar El Quijote en la cultura europea. Mito y representación (Ref. CEMU-2012-017-C01) dirigido por Begoña Lolo. La ópera contó con la dirección musical de José Ramón Encinar y la escénica de Santiago Sánchez. 
dos o apoyados por las instituciones estatales en algunas ocasiones, que ejemplifican las posibilidades habitualmente utilizadas para la conmemoración musical del campo cervantino, con partituras, grabaciones y estudios de algunas destacadas obras de este amplio repertorio. Es precisamente en ese campo en el que destacó sin duda la programación ofrecida en México por el Festival Internacional Cervantino (FIC) de Guanajuato, el encuentro artístico y cultural de mayor predicamento en el mundo iberoamericano ${ }^{7}$. En este año del cuarto centenario de la muerte de Cervantes, el Festival Internacional Cervantino, que llegaba a su XLIV convocatoria, presentó una edición especial en torno a tan importante celebración, y reunió destacadas expresiones de teatro, música y danza sobre el tema, con el título genérico de Cervantes 400. De la locura al idealismo. Al mismo tiempo se abrió un espacio a la reflexión y discusión sobre su obra y vigencia y para ello, Guanajuato, nombrada en 2005 por la UNESCO como la Capital Cervantina de América, unió en esta ocasión el FIC al Coloquio Internacional Cervantino, otra de las grandes apuestas sobre el cervantismo de la ciudad, que en esta ocasión llegó a su XXVI edición con el tema central de Trascendencia de Cervantes en las Artes.

Celebrado del 2 al 23 de octubre de 2016, el Festival contó con una oferta amplísima de más de 700 actividades y con España como país invitado especial. La apuesta por el repertorio musical cervantino, amplia y transversal, destacó en primer lugar en su mirada hacia el mundo de la ópera, con un acercamiento a ejemplos del repertorio cervantino desde el barroco hasta la música del siglo XX. Así, el Teatro Comunale di Bologna presentó su puesta en escena de la obra Don Chisciotte, compuesta en 1746 por el franciscano Giovanni Battista Martini, un interludio cómico-musical, pieza breve para ser representada durante los entreactos de una ópera, que fue un género muy típico en el barroco. A ello se añadió, en interpretación del británico Dunedin Consort, la conocida mascarada The Comical History of Don Quichotte (16941695), con música de Henry Purcell, John Eccles y otros compositores, y libreto de Thomas d'Urffey, así como el divertimento teatral en un acto de Antonio Salieri Don Quichotte alle nozze di Gamace (1771), con la compañía francesa Les Nouveaux Caractères. El siglo XX quedó representado por El retablo de las maravillas (Das Wundertheater, 1949), del compositor alemán Hans Werner Henze, con la puesta en escena de la Ópera de Cámara del Teatro Colón de Buenos Aires.

Otra de las versiones escénicas del mundo cervantino que se presentó fue, desde la óptica de la tradición teatral china con el espectáculo Don Quijote, el caballero andante, de la Ópera de Pekín de Guizhou, con 40 músicos y

7. El festival tiene su origen en la actividad teatral sobre los entremeses de Cervantes iniciada en 1953 por Enrique Ruelas, profesor de la Universidad de Guanajuato, que entre junio y septiembre de 1972 realizó un primer Coloquio Cervantino. El Gobierno mexicano se interesó pronto en ampliar la temática del evento, y en octubre de ese mismo año se consolidó el primer patronato del Festival Cervantino, con la celebración en esas fechas de la primera edición del mismo. 
actores en escena ${ }^{8}$. La presencia de la Orquesta Nacional de España (ONE), como invitada al evento, tuvo una de sus propuestas también en torno al mundo de la ópera, en versión de concierto, con la interpretación de la obertura de la ópera de Saverio Mercadante Don Chisciotte alle nozze di Gamac$c{ }^{9}{ }^{9}$. A ello se añadió la apuesta por la creación contemporánea con una obra encargo de la propia ONE para el Festival Internacional Cervantino, Los trabajos de Persiles y Segismunda, del compositor peruano Jimmy López, basada en la gran obra cervantina y articulada como una sinfonía en cuatro movimientos ${ }^{10}$.

El repertorio cervantino protagonizó también conciertos monográficos como el recital Don Quijote al piano, realizado en colaboración con el XXVI Coloquio Cervantino, que se articuló en dos partes: en la primera, quien suscribe estas líneas interpretó Don Quixote (1908), suite para piano de Erich. W. Korngold, y Don Quijote (1957) suite de danzas del ballet homónimo de Roberto Gerhard ${ }^{11}$, y en la segunda, el pianista mexicano Alejandro Barañón presentó su transcripción pianística del poema sinfónico Don Quixote, op. 35 (1897) de Richard Strauss. Ambos pianistas ofrecieron una conferencia previa con análisis de las obras interpretadas. Además de figurar monográficamente en estas propuestas, el amplio repertorio musical cervantino entrecruzó todo el festival, con la presencia de distintas obras dentro del programa general de gran parte de los conciertos, lo que dio gran coherencia a la propuesta especial del año. La suite-obertura para cuerda y continuo Burlesque de Quixotte, TWV 55: G10, de G. Ph. Telemann se escuchó en la interpretación de la Orquesta Barroca de la Universidad de Guanajuato; Don Quixotte, humoresque op. 87 (1869) de Anton Rubinstein, llegó en versión de la Orquesta Sinfónica de la Universidad de Guanajuato, y el Homenaje a Cervantes (1947), para dos oboes y orquesta de cuerda, del compositor mexicano Juan Pablo Moncayo, en la interpretación de la Orquesta de Cámara de Bellas Artes, propuestas todas que enriquecieron activamente esta variada oferta del amplio mundo del cervantismo musical.

La visión de Cervantes se acercó también a otros repertorios y estilos como el jazz con Alberto Zuckerman Trío y su concierto Don Quijote en jazz, o el rap, que tuvo un protagonismo destacado con un concurso que llevó los versos cervantinos al estilo de recitado rítmico característico de este género musical. Una iniciativa impulsada conjuntamente desde España y México, que

8. Una producción que se había presentado en España y Europa por primera vez en Barcelona en 2014.

9. Estrenada en 1830 en Cádiz, la obra se recuperó en transcripción de Adela Presas. Fue interpretada por primera vez en esa recuperación el 17 de octubre de 2015 en el Auditorio de Madrid en el XLIII Ciclo de Grandes Autores e Intérpretes de la Música de la UAM, por la Orquesta Verum, fruto del Proyecto de Excelencia Multidisciplinar de la UAM Quijote y Música. Véase Presas (2006).

10. Estrenada bajo la dirección de David Akhfam en el Auditorio Nacional en Madrid el 30 de septiembre y en Guanajuato el 11 de octubre, en el Teatro Juárez.

11. Obras y estudio introductorio recogidas en Don Quijote al piano. Ana Vega Toscano, piano (vol. 1 de la colección Música y Cervantes, dir. Begoña Lolo). Columna Música 1CM 02332009. 
contó primero con una cita en julio en el Festival de Teatro Clásico de Almagro, en la que ganó el rapero malagueño BTA, y la final en Guanajuato durante el FIC, con el triunfo del rapero mexicano Montiverso.

La importancia del personaje de don Quijote en el mundo del ballet y la danza ha sido también muy destacada, y el festival decidió acercarse a ese apartado centrando su oferta en una de las creaciones más populares, el ballet Don Quijote, estrenado en 1869 con música de Ludwig Minkus y coreografía de Marius Petipa ${ }^{12}$. Tres fueron las compañías que presentaron sus versiones y visiones de este clásico del ballet ruso. En primer lugar, la Compañía Nacional de Danza, con coreografía de José Carlos Martínez basada en las coreografías anteriores de Petipa y Gorsky ${ }^{13}$. A ello se unió la versión del Joven Ballet de Jalisco y, por último, la del Ballet Nacional de Holanda, bajo la dirección de Ted Brandsen, con la coreografía de Alexei Ratmansky, artista residente del American Ballet Theater, que también parte de las coreografías clásicas ya citadas.

Y junto a los conciertos y representaciones, esta gran cita cervantina ofreció también reflexión y estudio sobre Cervantes y su obra en el marco del XXVI Coloquio Cervantino Internacional ${ }^{14}$, celebrado del 2 al 6 de octubre, que en el terreno de la música contó con la ponencia ofrecida por Pepe Rey (2017), Apuntes e hipótesis sobre Cervantes, sus personajes y la música. En el coloquio se presentó igualmente la edición de las actas del año anterior, en las que de nuevo la investigación sobre el cervantismo musical había estado presente con la aportación de Begoña Lolo (2016a).

Con el apartado de la investigación cerramos el resumen de las múltiples actividades realizadas en el FIC de Guanajuato 2016, y a la vez enlazamos con otras ofertas dentro de ese mismo campo en otros escenarios, ofertas que fueron igualmente variadas. La música y la danza estuvieron presentes en congresos como el organizado en la Universidad de Alcalá de Henares bajo el epígrafe La Recepción de Cervantes en los siglos XX y XXI. Mitos y leyendas (5-7 de octubre 2016), y protagonizaron el congreso Las músicas de Cervantes: del patrimonio histórico a su recepción musical (s. XVI-XXI), convocado por el Centro de Investigación y Documentación Musical de Castilla-La Mancha, del 21 al 24 de septiembre. Igualmente, el cervantismo musical tuvo un apartado en el IX Congreso Nacional de la Sociedad Española de Musicología organizado en la Universidad Autónoma de Madrid del 16 al 19 de noviembre, con el espacio centrado en Cervantes en el tiempo: la

12. Petipa hizo dos versiones, una de ellas con un acto extra. En 1901 el coreógrafo Alexander Gorsky retomó el ballet y agregó algunas danzas.

13. Estrenada el 16 de diciembre de 2015 en el Teatro de la Zarzuela de Madrid.

14. El primer Coloquio Internacional se realizó en 1987, coincidiendo con la inauguración del Museo Iconográfico del Quijote en Guanajuato, impulsor de este encuentro que anualmente reúne a las más destacadas personalidades del cervantismo internacional. 
función de la reescritura ${ }^{15}$. Las grandes exposiciones también tuvieron su espacio para las músicas cervantinas, como fue el caso de la organizada en el Consejo Superior de Investigaciones Científicas bajo el título de Cervantes y el CSIC, que se abrió en abril de 2016 en la sede central del organismo en Madrid $^{16}$, en el que figuró una aportación musical llevada a cabo por la Institución Milá y Fontanals, con partituras, grabaciones y estudios. La música estuvo también presente en la Real Academia de Bellas Artes de San Fernando con el ingreso como académica de Begoña Lolo, catedrática de la Universidad Autónoma de Madrid y directora del Centro Superior de Investigación y Promoción de la Música, quien leyó el 18 de diciembre su discurso de ingreso bajo el título de El Quijote como fuente de inspiración en la creación musical, enmarcando el contenido en el contexto del año del centenario de la muerte de Cervantes ${ }^{17}$.

La presentación durante el año de portales en la web con acceso directo a importantes fondos ha sido uno de los aspectos más destacados: en este sentido, ha tenido también un apartado musical la importante catalogación y digitalización del fondo cervantino de la $\mathrm{BNE}^{18}$, un gran esfuerzo que ha posibilitado el acceso online desde la Biblioteca Digital Hispánica a un gran número de partituras impresas y manuscritos, que son de gran relevancia para la investigación y recuperación de tan rico patrimonio. Esta colección cervantina de partituras de la BNE consta de más de trescientos ejemplares, fechados desde el siglo XVIII hasta nuestros días. El grupo de música impresa está compuesto por 283 partituras, y en cuanto a manuscritos, hay en torno a una treintena de piezas con algunos autógrafos de compositores españoles. También la BNE aporta una interesante colección de registros sonoros de carácter cervantino en muy distintos soportes, desde rollos de pianola hasta discos compactos. Desde un punto de vista audiovisual, Radiotelevisión Española realizó su propio portal para el $400 .{ }^{\circ}$ aniversario ${ }^{19}$, con interesantes aportaciones para el estudio de las músicas incidentales realizadas en las principales producciones cervantinas impulsadas desde RTVE.

\section{BIBLIOGRAFÍA CITADA}

Lolo, Begoña (2016a). "Creaciones musicales basadas en el Quijote de 1615", en El Quijote de 1615, XXV Coloquio Cervantino Internacional. Guanajuato: Museo Iconográfico del Quijote, pp. 227-246.

15. Desde el año 2000, el equipo de investigación musicológica de la UAM se unió al estudio de la obra cervantina a través del análisis de forma sistematizada del repertorio musical cervantino en todos sus aspectos, con varios proyectos de investigación dirigidos por Begoña Lolo (Lolo y Presas 2014).

16. Reseñada por Martínez Olmo, M. del Pilar (2016).

17. Lolo 2016b. Discurso que contó con la contestación de Antonio Gallego.

18. Accesible en: $<\mathrm{http}: / /$ cervantes.bne.es/es/colecciones/musica $>$.

19. Accesible en: $<\mathrm{http} / / / \mathrm{www} . r \mathrm{rtve} . \mathrm{es} / 400$-cervantes $>$. 
Lolo, Begoña (2016b). Don Quijote como fuente de inspiración en la creación musical. Madrid: RABASF.

Lolo, Begoña y Adela Presas (2014). "Cervantes y el Quijote en la música. Pasado y presente", en Emilio Martínez Mata y María Fernández Ferreiro (coords.), Comentarios a Cervantes. Actas del VIII Congreso Internacional de la Asociación de Cervantistas. Oviedo: Fundación M. ${ }^{\text {a }}$ Cristina Masaveu Peterson, pp. 153-166.

Martínez Olmo, M. ${ }^{a}$ del Pilar (2016). "Cervantes y el CSIC", Anales Cervantinos. 48, pp. 361-367.

Presas, Adela (2006). "Don Quijote en la ópera italiana del siglo XIX. Don Chisciotte alle nozze di Gamazio, de Saverio Mercadante", en Alexia Dotras Bravos (coord.), Tus obras los rincones de la tierra descubren. Actas del VI Congreso Internacional de la Asociación de Cervantistas. Alcalá de Henares: Asociación de cervantistas, pp. 623636.

Presas, Adela (2007): "1905: la trascendencia musical del III Centenario", en Cervantes y el Quijote en la música. Estudios sobre la recepción de un mito. Madrid: Centro de Estudios Cervantinos, pp. 285-305.

Rey, Pepe (2017). "Apuntes e hipótesis sobre Cervantes, sus personajes y la música", en Trascendencia de Cervantes en las artes, XXVI Coloquio Cervantino Internacional. Guanajuato: Museo Iconográfico del Quijote, pp. 319-344.

Vega Toscano, Ana (2009). "Las aventuras de Don Quijote a través del piano", en Begoña Lolo (coord.), Don Quijote al piano. Vol. 1. Colección Música y Cervantes. Columna Música 1CM 0233, pp. 3-6.

Recibido: 19 de noviembre de 2017

Aceptado: 3 de septiembre de 2018 